DOI 10.4467/25439561KSR.21.007.14418

FRANÇOISE LESOURD (D) https://orcid.org/0000-0002-4347-5482

Université Jean Moulin Lyon 3

Lyon

\title{
СОВРЕМЕННЫЙ ВЗГЛЯД НА ЛИЧНОСТЬ И ТВОРЧЕСТВО НИКОЛАЯ ФЁДОРОВА
}

\section{CONTEMPORARY INSIGHT INTO NIKOLAI FYODOROV'S PERSONALITY AND WORKS}

Резюме

В настоящий момент во Франции переводится и готовится к первой публикации Философия общего дела Николая Фёдорова. Данная статья - о том впечатлении, которое испытывает читатель, сталкиваясь с такой необычной творческой личностью, и о трудностях, которые возникают при переводе. Грандиозный проект Фёдорова воскрешение отцов и население других планет - поражает своей «фантастичностью» (по словам Вл. Соловьёва). Однако он ставит на первый план созидательные возможности человека, и в этом предваряет ранние интеллектуальные тенденции советского времени. С другой стороны, озабоченность Фёдорова истощением земных ресурсов особенно созвучна с нашей эпохой. Всё это изложено русским мыслителем на особом языке, насыщенном архаизмами и литургическими терминами. В статье также рассматривается созвучие философии Н. Фёдорова с учениями К. Маркса, О. Шпенглера, Ч. Дарвина, подчёркиваются пересечения с Евангелием.

\section{Abstract}

The "Philosophy of the Common Task" by Nikolai Fyodorov is being translated and published for the first time in France. This article is about the impression that the reader has when faced with such an unusual creative mind, and about the difficulties that arise during translation. Fyodorov's grandiose project - the resurrection of the "fathers" and the popula- 
tion of other planets - is striking in its "fantasticness" (according to Vladimir Solovyov). However, he puts in the foreground the creative possibilities of man, and on this point it anticipates the early intellectual currents of the Soviet era. On the other hand, Fyodorov's concern about the depletion of earthly resources is especially consonant with our era. All this is stated in a special language, full of archaisms and liturgical terms. The article is focused on the consonances of N. Fedorov's philosophy with the teachings of K. Marx, O. Spengler, C. Darwin, also intersections with the Gospel are emphasized in a new way.

Ключевые слова: Философия общего дела, русская философия, русский космизм, Евангелие, воскрешение, истощение земных ресурсов

Keywords: Philosophy of the Common Task, Russian philosophy, Russian cosmism, Gospel, resurrection, depletion of earthly resources

Сейчас во Франции переводится и готовится к первому изданию Философия общего дела Николая Фёдорова, вместе с большим количеством его религиозных, краеведческих и философских статей. Это должно стать настоящим открытием, хотя русский космизм уже некоторое время назад обратил на себя внимание французской публики.

Трудно себе представить такую необыкновенную личность, как личность Николая Фёдорова. Своим образом жизни, так же как и своей мыслью в последние десятилетия XIX века, он стоял как бы на стороне от своих современников и в то же время, как ни странно, пользовался у духовной элиты России каким-то скрытым, но очень прочным авторитетом.

Это парадокс: сначала он преподавал в разных уездных городах, вёл скромную жизнь учителя истории и географии. Но слух о его необыкновенном учении распространялся, и у него рано появились ученики. Потом Фёдоров стал занимать совсем не престижную должность в библиотеке московского Румянцевского музея, в каталожном зале, но он пользовался глубоким почтением со стороны окружающих его людей, посетителей библиотеки, среди которых - Лев Толстой, Владимир Соловьев, Фёдор Достоевский. При описании его аскетической жизни (он жил в маленькой комнатушке, спал на одном сундуке без подушки, питался чаем, чёрным хлебом и сушёной рыбой) сразу возникает подозрение в некритическом, как бы агиографическом, отношении к предмету исследования. На самом деле изучение Фёдорова действительно ставит исследователя в сложное положение: дело даже не в том, что вся его энергия была посвящена осуществлению проекта всеобщего воскрешения и регуляции природы. По каким-то специфическим причинам, которые ещё предстоит определить, он уже сам по себе, своей личностью, своим темпераментом, представлял какое-то реальное осуществление той утопии, которую описывал в своих работах. 
О творчестве его в прямом смысле даже трудно говорить, поскольку он не оставил никаких законченных произведений, кроме своей Записки от неучёных к учёным (Вопрос о братстве, или родстве, о причинах небратского, неродственного, т. е. немирного, состояния мира и о средствах к восстановлению родства $a^{1}$. Как известно, этот своего рода трактат отвечает на запрос Достоевского, который вдохновился его «проектом» и просил изложить его как можно подробнее 2 . Другие разрозненные записки, оставшиеся после его смерти, были собраны и изданы его учениками, но непроданы, а распространены среди тех, кто интересовался Философией общего дела. Видимая разрозненность не мешала цельности замысла, стройности грандиозного проекта воскрешения мертвых, на который смотрели как на настоящее учение.

Как этот скромный, почти потаённый образ жизни человека, не претендующего на какую-либо известность, мог сочетаться с его бесспорным влиянием на творческую жизнь следующих поколений (особенно на русское искусство XX века), с таким широким, хотя и отчасти подспудным распространением его идей даже в советский период? Фёдоров был из тех мыслителей, которые твёрдо верят во власть идей и поэтому бескорыстно смотрят на всякую духовную деятельность. Совершенно закономерно его отрицательное отношение к авторским правам.

Многие авторы, в том числе и Сергей Булгаков, называли Фёдорова «московским Сократом». С древнегреческим философом его сближал не столько образ жизни, сколько устная форма, которую он часто придавал своему учению. Смерть его, спокойная и бесстрашная, также напоминает смерть Сократа. Но в то же время учение Фёдорова во многом противостоит сократовскому, особенно его отношению к истине: он не допускал того факта, что можно пребывать в истине отдельно от других. «Общее дело» состояло как раз в том, чтобы собрать всё человечество в поиске истины и в стремлении к правде, т. е. вернуть жизнь всем, кто её лишился. По мнению русского мыслителя, нет подлинного знания без действия, а действие должно быть общим для всех.

Первый шаг к воскрешению - возвращение к могилам отцов, и поэтому к деревенской жизни. Фёдоровское осуждение городской промышленной цивилизации и капитализма ставит его на один уровень с Марксом. Но, как мы знаем, антикапиталистические настроения в России были особенно живучи, и учение Фёдорова имеет общие черты со славянофильством и народничеством. Сельская община для него представляет образец идеального общества. Спло-

${ }^{1}$ Н.Ф. Фёдоров, Собрание сочинений в 5 томах, под ред. А. Гачевой и С. Семёновой, Москва, Прогресс, 1995, т. I, с. 27.

${ }^{2}$ С. Семёнова, Философия воскрешения Н.Ф. Фёдорова, [в:] Н.Ф. Фёдоров, Собрание сочинений..., указ. соч., с. 4. 
чённость определённого человеческого коллектива вокруг какого-нибудь общего дела (например, построения обычной церкви) предвосхищает возможность объединения всего человечества для воскрешения предков.

Фёдоров обличает пороки городской промышленной цивилизации с нравственной точки зрения. В его глазах, самый яркий пример всего зла, принесённого промышленной цивилизацией - парижская всемирная выставка 1889 года, организованная по случаю столетия французской революции:

«Всемирная выставка как указание значения города (или городской, европейскоамериканской цивилизации и культуры) - значение города, заключающееся в отрицании цели и смысла жизни. Выставка есть изображение измены отцам сынами, увлекшимися красотою женщин; это дефратернизация чрез депатриацию, или экспатриация для служения женщинам, эффеминизация» ${ }^{3}$.

То, что пришлось обратиться к французскому языку, чтобы определить все эти пороки, по мнению Фёдорова, хороший признак: всё это настолько чуждо русскому духу, что в русском языке не нашлось подходящих слов.

Конечно, в своей критике городской цивилизации Фёдоров не оригинален, он продолжает целую традицию. И в то же время он предвосхищает позицию Шпенглера, который примерно два десятилетия спустя усмотрит в «чисто городском мировосприятии» одну из причин заката европейской цивилизации:

«Мировой город означает: космополитизм вместо „отчизны“, холодный фактический смысл вместо благоговения перед преданием и старшинством, научная иррелигиозность как петрефакт преставившейся религии сердца...» ${ }^{4}$.

Как известно, Закат Eвpоnь (Der Untergang des Abendlandes) был опубликован впервые в 1918.

Основной двигатель городской цивилизации - так называемый прогресс. Долгое время прогресс представлялся многим как своего рода добровольная жертва ныне живущих поколений ради будущих (это позиции Базарова в романе Ивана Тургенева Omu̧ы и детu). Но конец XIX века был уже далёк от таких настроений. К тому же, тогда уже появились теории Николая Данилевского и Константина Леонтьева о культурных типах, которые рождаются, проходят этап так называемой цветущей сложности, а затем и постепенно умирают. Они ставили под вопрос идею прямолинейного необратимого прогресса.

${ }^{3}$ Н.Ф. Фёдоров, Собрание сочинений..., указ. соч., с. 460.

${ }^{4}$ О. Шпенглер, Закат Европьы. Очерки морфологии мировой истории, пер. с немецкого К. А. Свасьяна, Москва, Издательство «Мысль», 1998, с. 166. 
Радикальное отрицание прогресса у Фёдорова оригинально для его времени: для него эта идея сама по себе нравственно неприемлема: она предполагает, что дети «поглощают» отцов: «в царстве прогресса дети господствуют над отцами»5. В первой части Записки учёным от неучёных он даёт резко полемическое определение прогресса:

«Прогресс в совершеннейшем виде является в животном царстве. Животные не только не заботятся о старшем поколении, а даже убивают своих стариков. У человека этот порок, т. е. прогресс (антагонизм младшего поколения к старшим), смягчается; но как бы ни смягчали порок, он все же останется пороком; младшее поколение, пользующееся старшими как орудием для своего возвышения, обращающее их в свое подножие, своим превозношением попирающее их, ни в каком смысле не может быть возвышением, улучшением, ни внутри (в мысли, в душе), ни вовне» ${ }^{6}$.

Чередование поколений само по себе зло, своего рода дурная бесконечность. Она противопоставляется идее «собирания» в общем деле, для воскрешения отцов. Если оставить в стороне фантастику воскрешения всех мёртвых и населения космических пространств, остаётся существенный нравственный вопрос: бесчувственное отношение новых поколений к старшим - они фактически их вытесняют, «поглощают». Георгий Флоровский упрекал Фёдорова в «нечувствии греха» ${ }^{7}$. Лучше сказать, что у него понятие греха смещается: самый страшный грех-это забвение отцов, безразличное отношение к их смерти. Первоначальный грех - падение, после которого появилась смерть. Победить смерть (возродить отцов) значит вернуться в состояние первоначального совершенства:

«[...] воскрешение есть замена исторического процесса, эволюции, прогресса, замена того, что само собою делается, т. е. рождается, а потому и умирает; [...] переход $[\ldots]$ от села в город есть процесс естественный, в котором следуют, отдаются слепому животному влечению, и напротив, обратное движение, движение к селу, к праху предков, было бы движением нравственным, вытекающим из сознания вреда и блага для целого рода, и такое движение было бы одним из моментов дела воскрешения» ${ }^{8}$.

\footnotetext{
${ }^{5}$ Н.Ф. Фёдоров, Собрание сочинений..., указ. соч., с. 445.

${ }^{6}$ Там же, с. 67.

${ }^{7}$ Г.В. Флоровский, Пути русского богословия, Париж, Ymca-Press, 1988, с. 324.

${ }^{8}$ Н.Ф. Фёдоров, Собрание сочинений..., указ. соч., с. 395.
} 
Мысль эта весьма закономерна, поскольку проект Фёдорова - всеобщее воскрешение, одна из центральных тем его творчества - смерть. Однако парадоксально, что нет ничего болезненного или мрачного даже в тех его текстах, где рассматривается вопрос о кладбищах, о том центральном месте, которое они должны занимать в жизни сельчан (как место поминания усопших). В главном труде Фёдорова, в Вопросе о братстве, или родстве, о причинах небратского, неродственного, т. е. немирного, состояния мира имеется описание того, как должно выглядеть кладбище:

«Если истинная наука ограничит памятник крестом, поставленным пред могилою, с лицевым изображением у подножия креста погребенного с его деяниями, представленными символически, то этим она не ограничит содержания памятника, а беспредельно расширит его; в таких памятниках будет много умственной, сердечной работы. Снимки с лицевых изображений, собранные и помещенные под общий крест, обнимающий их своим подножием, т. е. Голгофою, составляют лицевой синодик, музейский иконостас, заменяющий портретную галерею; это собор всех (местных) умерших отцов, требующий собора всех живущих сынов и научающий их тому, что нужно делать» 9

Кладбище в сочетании с музеем и храмом соединяет знание (всего прошлого, отцов) с действием (показывая, что делать). Стоит заметить, что всё это - «лицевой синодик», «музейский иконостас» - на грани абстракции. Поминание усопших сводится к набору ритуальных изображений: всё должно быть сохранено, память обо всём - в перспективе всеобщего воскрешения. Тут ничего нет болезненного, никакой тяги к некромантии, вопреки тому, что утверждает Георгий Флоровский ${ }^{10}$. Нет натуралистических деталей по поводу трупов, мертвецов. В те редкие случаи, когда слово «труп» встречается в тексте, оно появляется в связи с тем, что Фёдоров затрагивает «санитарный вопрос», т. е. вопрос о том, как избежать эпидемий в условиях близости к могилам.

Смерть скорее всего сводится к абстракции, так же, как и жизнь. Она лишена чувствительного, осязаемого содержания. Одна особенность этого учения в том, что оно лишает чувствительного содержания то, что оно намеревается восстановить, вернуть к жизни. Так, по крайней мере, может смотреть на этот проект женщина - главная преграда для его осуществления: «Смотреть на землю как на жилище, а не как на кладбище - значит прилепиться к жене и забыть отцов, а всю землю обратить в комфортабельное обиталище (гнездо), т. е. это значит смотреть на нее как на земное, а не как на небесное

\footnotetext{
${ }^{9}$ Там же, с. 67.

${ }^{10}$ Г.В. Флоровский, Пути русского богословия..., указ. соч., с. 323.
} 
тело...» $\rangle^{11}$. Тут нужно помнить о странной особенности повседневной жизни самого Фёдорова, как бы лишённой житейского чувствительного содержания.

Роль и значение женщины у Фёдорова заслуживают особого изучения. Они могут показаться противоречивыми. Не надо забывать, что если Троица в его глазах - образец для любого человеческого общества, то она не может быть лишена женского начала:

«Если в учении о Троице Дух не будет представлен образцом для дочери, то сама Троица обратится в безжизненную, монашескую, платоновскую, или платоническую; если же дочь не будет подобием Св. Духа, не будет духом любви, то проникнется духом разрушения, нигилизма» ${ }^{12}$.

Прежде всего женщина олицетворяет чувственность, ради удовлетворения которой как раз и существуют современная промышленная городская цивилизация, «фабрика», «мануфактура», «выставка», и мужчины отворачиваются от могил отцов, от родового быта.

«Ассамблеи ${ }^{13}$ есть общество эмансипированных женщин, т. е. освобожденных от власти родителей и забывших отцов (блудные дочери), подчинивших себе мужчин (сынов), которые также забыли отцов (блудные сыны)»14.

Женщина - скрытый двигатель того общества, которое имеет целью наслаждение. «Полным падением был бы всеобщий гетеризм, или стадное состояние; но это только идеал, мечта, утопия гражданского общества, и притом только тех из общества, коих называют передовыми» ${ }^{15}$. Под выражением «гражданское общество», Фёдоров подразумевает простых обывателей, не военных и не духовных лиц - тех, кто не служит - и не крестьян, от которых зависит насущная жизнь всего общества.

Чтобы охарактеризовать власть женщины в городской цивилизации конца XIX века, Фёдоров перенял у Дарвина выражение «половой отбор», слегка меняя его значение, подчёркивая пагубное влияние женщины на эволюцию всей современной цивилизации:

\footnotetext{
${ }^{11}$ Н.Ф. Фёдоров, Собрание сочинений..., указ. соч., с. 70.

${ }^{12}$ Там же, с. 90.

${ }^{13}$ Ассамблеи - это пышные официальные балы, которые организовались во Франции в эпоху Третьей республики - F. L.

${ }^{14}$ Н.Ф. Фёдоров, Собрание сочинений..., указ. соч., с. 464.

15 Там же, с. 86.
} 
«Женщина, пользуясь всеми произведениями фабрик и заводов для соблазна мужчин, заставляет и сих последних пользоваться произведениями тех же фабрик и заводов, чтобы и в свою очередь путём соперничества друг с другом действовать на неё, на женщину» ${ }^{16}$.

Где грань между чувственностью и чувствительностью? Промежуточный слой восприятия между этими двумя понятиями (то, что относится к органам чувств, без оценочного суждения) в русском языке определить нелегко. В личности же самого Фёдорова он как бы просто отсутствует. Конечно, специалисты утверждают, что он совсем не претендовал на то, чтобы навязать свой необыкновенный образ жизни посторонним людям, даже близким. Однако мы знаем, как он настаивал на том, что нельзя привязываться к вещам. И трудно предполагать, что его великий проект ничего не имел общего с его личностью.

Можно задать себе вопрос: не нужно ли ему, в конечном итоге, избавиться от всего ощутимого, от ощутимой наполненности жизни для того, чтобы жизнь и смерть слились в одно? В проекте Фёдорова идеальная (или допустимая) женщина целиком посвящается поминанию отцов:

«К сим последним, к неоставлявшим отеческих преданий, принадлежат женщины земледельческого класса, у коих преданность к родителям выражается преимущественно в погребальной обрядности, утратившей ныне свой истинный смысл» ${ }^{17}$.

Идеал женщины - сельская женщина, которая готовит у семейного очага погребальные трапезы. Такими должны быть все «дочери человеческие, ставшие „как одна““ дочь, преданная отцам». Ситуации, где речь идёт о женщине как о супруге и матери, об орудии всеобщего примирения, отсылают нас к XVIII веку, к идиллии, с одними и теми же условными позами и ситуациями, почти без реального жизненного содержания.

К механистическому представлению о человеческом организме («Приходится, однако, напомнить [...] что организм - машина и что сознание относится к нему, как желчь к печени; соберите машину - и сознание возвратится к ней!» ${ }^{18}$ ) присоединяется у Фёдорова идея сохранения материи - закон, который позволяет восстановить тела умерших. В этом процессе важную роль играет археология: археология в обширном смысле, наука, «которая, руко-

\footnotetext{
${ }^{16}$ Там же, с. 463.

${ }^{17}$ Н.Ф. Фёдоров, Собрание сочинений..., указ. соч., т. II, с. 69.

${ }^{18}$ Н.Ф. Фёдоров, Собрание сочинений..., указ. соч., т. I, с. 264.
} 
водимая чутким сердцем сыновей, разыскивает рассеянные частицы отцовского праха» ${ }^{19}$. Закон сохранения материи даёт право думать, что когда-нибудь будет восстановлено целое человеческое тело, когда соберут одну за другой все его рассеянные частицы:

«Представим же себе, что мир, вдруг или не вдруг, осветился, сделался знаем во всех своих мельчайших частицах, - не будет ли тогда для нас ясно, какие частицы были в минутной дружбе одна с другой, в каком доме или организме они гостили вместе или какого целого они составляли часть, принадлежность?» ${ }^{20}$

Эта концепция материи как некоего континуума (пространственного так же, как и временного) даёт нам понять, почему Фёдоров оказал такое влияние на художников, особенно на Павла Филонова. В картинах последнего идея непрерывной материи становится как бы наглядной. Художники русского авангарда ставили себе целью пересоставить, пересоздать формы живого мира - это то же пересоздание, восстановление реальности благодаря человеческому труду, что и в Фёдоровской утопии.

Человеческой деятельности отводится такое исключительное место (участвовать в процессе воскресения), что невольно возникает впечатление какого-то прометеевского устремления. Однако сам Фёдоров настаивал не на какой-либо чрезмерной власти или мощи человека, а скорее всего на предельной, можно сказать чудовищной, ответственности его как соучастника в Божьем деле. Прометеевские тенденции, очевидные в советской культуре первых десятилетий, скорее всего являются лишь непредвиденным последствием его учения.

В связи с этим стремлением перестраивать весь мир по-новому на первый план выступает понятие организации. Организация определяет художественную композицию картины так же, как функционирование общества. Она, казалось бы, имеет первенство над индивидуальной личностью. Но тут опять возникает парадокс: Фёдоров всегда подчёркивает абсолютное значение каждой личности. Он повторяет, что единство не имеет ничего общего с однообразием:

«Хотя в наше время много говорится о личности, а между тем не принимается не только никаких мер для сохранения личных особенностей, а даже всё делается для уничтожения их, потому что однообразие принимается за единство» ${ }^{21}$.

\footnotetext{
19 Там же, с. 244.

${ }^{20}$ Там же, с. 199.

${ }^{21}$ Там же, с. 367.
} 
И всё же, новое общество, которое ставит себе целью воскрешение мертвых, должно быть строго организовано, как механизм.

Фёдоров очень много внимания посвящает архитектуре, росписи стен. Он подробно описывает кладбища, церкви и музеи. Сохраняя память об умерших, церкви-школы имеют воспитательную функцию в перспективе всеобщего восстановления. Кропотливое описание церквей и музеев напоминает о тесных связях между архитектурой и утопией. Церкви-школы, музеи-обсерватории имеют много общего с проектами Клод-Никола Леду ${ }^{22}$, французского архитектора XVIII века, который особенно ясно выражает утопический дух своего времени. Строгая пространственная организация и точное распределение всех видов деятельности должны придать максимальную эффективность человеческому труду. В конечном счёте получается стройность, но стройность трудно совместимая с личной свободой. Несмотря на утверждения самого Фёдорова, место, предоставленное личной свободе в проекте воскрешения, не совсем ясно. Это кропотливое устройство общества и человеческой деятельности заслужило у Флоровского название «насильнический утилитаризм» ${ }^{23}$.

Чрезмерное значение, которое придаётся созидательным способностям человека, в конце концов роднит любую деятельность его с художественным творчеством. Наверное поэтому космизм и прежде всего «фёдоровизм» оказали такое заметное влияние на искусство (на живопись и на литературу). Как известно, Фёдоров утверждал, что «наше тело должно быть нашим делом»: человек должен быть в силах сам пересоздать своё собственное тело. Однако наделение тела таким значением не подразумевает никакой чувственности или сосредоточенности на его физическом облике (т.е. стремлении кпредполагаемой красоте):

«Соображаться с устройством нашего организма, который есть бессознательное произведение наших пороков, не может быть принято за правило нашего поведения; наше тело должно быть нашим делом, но не эгоистическим самоустроением, а делом, через возвращение жизни отцам устрояемым» ${ }^{24}$.

Дух самоотречения, который пронизывает всёэто рассуждение, проявляется в том, что созидательные способности человека, от которых зависит осуществление «общего дела», целиком обращены на восстановление умерших, на воскрешение отцов. Из-за этого проект Фёдорова лишён прометеевского

\footnotetext{
22 Большая часть проектов К.-Н. Леду выставлена в Королевском солеваренном заводе в районе Ду (Saline Royale, Musée Claude-Nicolas Ledoux, Arc-et-Senans, Doubs).

${ }^{23}$ Г.В. Флоровский, Пути русского богословия, указ. соч., с. 330.

${ }^{24}$ Н.Ф. Фёдоров, Собрание сочинений..., указ. соч., с. 76.
} 
духа. И всё же по сути он недалёк от тех попыток переделки всего человеческого материала, которые возникли позже, от попыток коренным образом пересоздать, преобразить человека, которые объявились после революции, например, у поэтов Пролеткульта, в чьих стихах человек выглядит как своего рода металл, нуждающийся в переплавке.

Один из самых сложных вопросов, связанных с особым выявлением созидательных возможностей человека - отношение Фёдорова к христианству. Сам он утверждал, что весь его проект исходит из христианских догм. В его глазах образцом для любого человеческого коллектива должна быть Троица (пример нераздельности и неслиянности). Во многих местах его статей речь идёт о преимуществе православия перед другими исповеданиями. В своём постоянном испытании вер, утверждает Фёдоров, Россия всё время задумывалась над тем, что такое самая подлинная христианская религия. Владимир Святославович, прежде чем выбрать византийское христианство, предпринял как раз настоящее испытание разных вер. Именно потому, что Святая Русь по существу христианское царство (как утверждал уже Ермолай-Еразм в XVI веке), она и призвана исполнить христианский долг - воскресение плоти, воскрешение отцов. В учении Фёдорова мысли о судьбе человечества, о его единстве, исходят из Халкидонского символа, где говорится о двух сущностях Христа, а также из концепции Троицы (о «нераздельности и неслиянности» трёх ипостасей божества). Идея воскрешения опирается на догме о воскресении плоти. Уже Алексей Хомяков напоминал: «Не без тела воскреснем» ${ }^{25}$.

Но Фёдоров отбирает одну часть христианской традиции, чтобы поставить её в основу своей системы (и даже иногда слегка изменяет её). А ведь первая характеристика христианской традиции-еёцельность, но и её неоднозначность. Особенность евангельского свидетельства в его открытости, его полифоничности. Жан-Филипп Пьерон пишет в своей книге о философии свидетельства: «То, что каждый из евангелистов имеет свой голос, свою тональность [...], нас предохраняет от искушения абсолютизации» ${ }^{26}$. Евангельское свидетельство показывает историю с разных точек зрения, «но это только означает, что через историю абсолют проявляет себя и что нельзя абсолютизировать каждое из этих проявлений $»^{27}$. А Фёдоров, кажется, абсолютизирует часть евангельского свидетельства и, кроме того, интерпретирует его по своему, в зависимости от своей концепции. Его интерпретация скорее переносит нас в первые века

${ }_{25}$ А.С. Хомяков, Избранные сочинения, Нью-Йорк, Издательство имени Чехова, 1955, c. 207.

${ }^{26}$ J.-Ph. Pierron, Le passage de témoin, Paris, Cerf, 2006, с. 167. Здесь и далее перевод иностранных цитат на русский язык выполнен автором статьи, если не указано иначе.

${ }^{27}$ Там же. 
христианства, в кипение гностических учений, в религиозные круги, где писались апокрифы, чем в апостольскую церковь в строгом смысле.

Иногда Фёдоров свободно наделяет новым толкованием религиозные тексты и даже открыто их изменяет. Самое показательное место - в самом начале второй части Записки от неучёных кучёныл. Там мы читаем: «Возвратить сердца сынов отцам (Ев. Луки 1, 17 - применительно к нашему времени, вместо „сердца отцов детям“, как в Евангелии) - это и есть дело Божие» ${ }^{28}$. Он сам сознательно меняет текст Евангелия, и, кажется, не испытывает при этом никакой неловкости.

Но чаще всего он не меняет текст, он как бы идёт дальше того, что говорится в Евангелии, и в этом проявляет замечательную проницательность. Так, рассказ о том, что произошло в Вифании, приобретает в его религиозных текстах символическое значение. Этот эпизод присутствует и в Евангелии от Матфея, и в Евангелии от Иоанна. Фёдоров сливает оба повествования: в Вифании, по Иоанну, состоялась первая обедня «за шесть дней по Пасхи». В отличие от Вифлеема, где Христос «не имел где голову преклонить», и от Иерусалима, где его осудил Синедрион, Вифания на короткое время предоставила ему приют. Фёдоров пишет:

«Это небольшое селение нужно поставить выше Вифлеема, не давшего места в своих стенах родившемуся Христу, выше Назарета, собиравшегося убить своего пророка, выше Иерусалима, убившего Его и не давшего места в своих стенах Умершему» ${ }^{29}$.

Тут сосредоточены все излюбленные темы Фёдорова: воскрешение (ибо тут как раз находился Лазарь); объединение всех, поскольку на этой обедне присутствовала целая толпа. Более того, согласно Евангелию от Матфея, он прибавляет, что эта первая обедня состоялась в доме Симона прокаженного, когда-то исцелённого Христом. Симон был отцом Лазаря. В этом фрагменте нет ничего придуманного, просто собраны вместе данные из разных Евангелий. Картина вечери получается не тайной, а открытой всем и счастливой - как бы обратная сторона той вечери, которая должна была состояться шесть дней спустя. Следующая цитата очень показательна. Она исполнена настоящим вдохновением и показывает, как Фёдоров читал Евангелие:

«Таким образом Вифанская Великая Вечеря была, можно сказать, вселенским собором, в котором были представлены 12 колен Израилевых и 70 языков рода

\footnotetext{
${ }^{28}$ Н.Ф. Фёдоров, Собрание сочинений..., указ. соч., с. 61.

${ }^{29}$ Н.Ф. Фёдоров, Собрание сочинений..., указ. соч., т. II, с. 56.
} 
человеческого; здесь были и хананеи, осужденные ветхим законом на истребление; здесь были самаряне, презираемые иудеями и ставшие образцом милосердия; были здесь представители и главных направлений духа (ума) человеческого: фарисеи, к которым принадлежал раньше и сам хозяин, исцеленный одновременно и от физической, и от нравственной проказы - фарисейства; были здесь и саддукеи-эпикурейцы, образумленные и примиренные Христом-Воскресителем; ложно-веровавшие, бывшие неверующие и истинно веровавшие - все, в лице и в делах Воскресителя, нашли разрешение своих недоумений, сомнений и отрицаний, все пришли в согласие и в единство любви» ${ }^{30}$.

Описание этого огромного собрания - плод его воображения. Перед теми, кто упрекал его в измене Евангелию, Фёдоров оправдывался следующими соображениями: «И если нам скажут, что „нет в Евангелии“, мы ответим: там сказано, что Христос любил Вифанию, любил Лазаря, а этим сказано все» ${ }^{31}$. Это только один пример того, как он меняет тексты. Но стоит отметить, что он их обычно меняет в счастливую сторону: он воображает, как на первый малейший знак вся эта толпа поднялась бы в защиту обвинённого Христа. Как будто в его представлении «тёмный лик» христианства (по выражению Розанова) исчезает.

Эти вариации на темы священного писания свидетельствуют о возможном влиянии духовных стихов на творчество Фёдорова, тех стихов, которые читали «калики перехожие». В этом духе мыслитель развивает «духовный стих о двух братьях Лазарях» ${ }^{32}$, сочинённый на основе притчи о богаче и бедном Лазаре. Его переделка священных текстов близка к этому типу народного творчества.

Общеизвестна близость православия к начальному христианству, к духовному кипению первых веков христианства, с их множеством ересей или разновидностей христианства, когда оно ещё неуспело окончательно сформироваться. Фёдоров говорил от имени «неучёных», поэтому он испытывал симпатию к этим течениям, появившимся чаще всего в народной сфере. Парадоксальным образом эта симпатия сочетается с обширными знаниями в области первоначального христианства, как это особенно ярко проявляется в третьей части Записки от неучёных.

Мысль Фёдорова открывает доступ к некоторым специфическим особенностям религиозной жизни в России. То, что до начала XIX века не существовало никакого, по выражению Вл. Соловьева, «догматического развития» (систематического изложения главных пунктов веры), так как верность пра-

\footnotetext{
${ }^{30}$ Там же.

${ }^{31}$ Там же.

${ }^{32}$ Там же, с. 55.
} 
вославной церкви к постановлениям семи первых соборов запрещала что-либо прибавить к их формулировкам. Только в середине XIX века появился первый катехизис, почти в одно время с трактатом Хомякова Церковь одна, изданным уже после смерти автора, в 1864 году. Такая ситуация открывала парадоксальную свободу личным, не подчинённым никаким строгим богословским авторитетам, интерпретациям Священного Писания. В общей картине русского религиозного мышления Фёдоров с его установкой на воскрешение ушедших поколений уже не выглядит таким исключением. Установка эта безусловно исходит из христианства, но в ней усматривается целый комплекс свободных вариаций на избранные христианские темы, и в конечном итоге она доходит до положений, которые могут показаться чуждыми христианству.

Мысль о воскрешении мертвых, совершаемом благодаря стараниям объединённого человечества, выходит за каноническиерамки. Эта идея принадлежит Фёдорову. Следует подчеркнуть, что она напрямую связана с отрицанием трансцендентности. Люди должны объединиться, чтобы воскресать всех умерших предков здесь же, в настоящей действительности.

Более того, эта мечта не только о том, как восстановить всё, что было, но восстановить все вещи в их первичном совершенстве, в каком они были до Падения. Она характерна для первоначального христианства и носит имя апокатастасиса. Возражение Соловьёва о том, что наши мелочные пошлые жизни не заслуживают бессмертия ${ }^{33}$ здесь не имеет места, так как все призваны реально вернуться к предполагаемой первоначальной чистоте.

«Прием, оказанный блудному сыну, вознаграждение работника, пришедшего в последний час, наравне с первыми, - все это побледнело перед вступлением разбойника в рай. Но зато и никогда не было такой радости на небе, как в момент вступления разбойника, которого надо представлять себе воплощением всех грехов несчастного человечества. И эти грехи, непрощаемые, казнимые по закону ограниченной человеческой правды, оказались прощенными безграничною благостью Божией! Остался только Иуда... но ведь и Иуда раскаялся!» ${ }^{34}$

Идея апокатастасиса подразумевает, что рай не только для избранных, не для одних только праведников. В отличие от «ограниченной человеческой правды», Божья правда позволяет, чтобы все были спасены, чтобы все «пришли в разум истины». Однако концепция Фёдорова также означает, что совершенство мыслимо в здешней реальности, что было неприемлемо для Соловьева (об этом

${ }^{33}$ Вл.С. Соловьёв, Собрание сочинений, т. VII, Санкт-Петербург - Брюссель, Издательство «Жизнь с Богом», 1966, с. 31.

${ }^{34}$ Н.Ф. Фёдоров, указ. соч., т. II, с. 61. 
он пишет в Смысле любви) и можно предполагать, что Краткая повесть об Антихристе - косвенный ответ Фёдорову, который показывает, какой опасностью чревата идея о достижимости совершенства в самом историческом процессе.

Соловьев так же, как Фёдоров, верил в могущество человеческого действия. В реферате Об упадке средневекового миросозерцания у него есть удивительные слова: «от нас зависит, чтобы Христос воскрес в своём человечестве» ${ }^{35}$. Оба мыслителя всё-таки сходились в главном: общее дело спасения начинается здесь же, в этом мире. Страшный голод 1891 года, следствие страшной засухи, был настоящим толчком для их размышления над будущим окружающей среды и над спасением человечества (к тому же это совпадало с апокалиптическими настроениями конца века).

Осуждая промышленную цивилизацию и идею прогресса, Фёдоров отнюдь не отвергает научные и технологические достижения. От них же зависит, чтобы человечество сумело восстановить тела умерших отцов, частицу за частицей, а дальше освоить и населять космические пространства. Но в то же время именно наука должна помочь вернуться к архаичному образу жизни, патриархальному, деревенскому, где на место промышленности станет кустарное производство. Самые последние открытия науки должны служить деревенской утопии.

Работая над французским переводом Фёдорова, нам казалось, что мы стоим как бы между двумя крайностями в истории мысли: с одной стороны, проект воскрешения поражает своим архаизмом и даже фантастичностью, он относит нас к первым десятилетиям христианства, а с другой стороны, осознание того, что наша цивилизация непосредственно угрожает существованию человека и самой планеты поражает своей актуальностью.

\section{Литература}

Гачева А.Г., Русский космизм в идеях и лиц̧ах, Москва, Академический проект, 2019, $431 \mathrm{cc}$.

Соловьёв Вл.С., Собрание сочинений в XII mомах, Санкт-Петербург - Брюссель, Издательство «Жизнь с Богом», 1966.

Фёдоров Н.Ф., Собрание сочинений: в 4 mm., ред. А. Гачева и С. Семёнова, Москва, Прогресс, 1995.

Флоровский Г.В., Пути русского богословия, Париж, Ymca-Press, 1988, 603 сс.

35 Вл.С. Соловьёв, Об упадке средневекового миросозериания, [в:] его же, Собрание сочинений, указ. соч., т. V., с. 393. 
Хомяков А.С., Избранные сочинения, ред. Н.С. Арсеньев, Нью-Йорк, Издательство имени Чехова, 1955, 413 сс.

Шпенглер О., Закат Европьl. Очерки морфологии мировой истории. 1. Геитальт и действительность, пер. с немецкого К.А. Свасьяна, Москва, Издательство «Мысль», 1998, 663 сс.

Pierron J.-Ph., Le passage de témoin, Paris, Cerf, 2006, 320 cc.

\section{References}

Fedorov N.F., Sobranie sochinenii: $v 4$ tt. [Collected Works in 4 Volumes], A. Gacheva and S. Semenova (Eds.), Moscow, Progress Publ., 1995.

Florovskii G.V., Puti russkogo bogosloviia [Paths of Russian Theology], Paris, Ymca-Press Publ., 1988, 603 pp.

Gacheva A.G., Russkii kosmizm v ideiakh i litsakh [Major Concepts and Figures of Russian Cosmism], Moscow, Akademicheskii Proekt Publ., 2019, 431 pp.

Khomiakov A.S., Tserkov'odna: Opyt katekhizicheskogo izlozheniia ucheniia o tser$k v i$ [The Church Is One: Essay on the Unity of the Church], [in:] A.S. Khomiakov, Izbrannye sochineniia [Selected Works], N. S. Arsen'ev (Ed.), Chekhov Publ. House, New York, 1955, 413 pp.

Pierron J.-Ph., Le passage de témoin [Passing the Baton], Paris, Cerf Publ., 2006, $320 \mathrm{pp}$.

Solovyov V1.S., Sobranie sochinenii v XII tomakh [Selected Works in XII Volumes], St. Petersburg - Brussels, Catholic Publ. House "Life with God", 1966.

Spengler O., Zakat Evropy. Ocherki morfologii mirovoi istorii. 1. Geshtal't i deistvitel'nost' [The Decline of the West (Volume I): Form and Actuality], trans. K.A. Svas'ian, Moscow, Mysl' Publ., 1998, 663 pp. 